\title{
Discussions on Construction Technology of Supporting Frame Pedestal Base Steel Structure of High-rise Buildings
}

\author{
Lei Han ${ }^{1}$, Heng Zheng ${ }^{2}$, Chuanhong $\mathrm{Li}^{1}$ \\ ${ }^{1}$ Institute of Civil Engineering, Shandong Kaiwen College of science \& Technology, Shandong 250100, \\ China \\ ${ }^{2}$ Department of Railway engineering and civil engineering, Shandong Polytechnic, Shandong 250100, China
}

Keywords: high-rise building; steel structure; frame; column base construction

\begin{abstract}
The supporting frame pedestal base construction technology plays an important role in the construction of steel structure quality of high-rise building, the attention is an important link in the construction of steel structure of the high-rise building. In this paper, the tower No. 1 CRE International Plaza is taken as the research object, to explore the optimization measures of high-rise steel structure frame column base construction technology support, hoping to provide reference to improve the quality of high-rise building.

With the development of the social economy, the high-rise buildings in China stand up and become an important trend in the China's construction industry. The steel structure in the high-rise building has become more and more common, which has been widely recognized and applied, and its industrialization and commercialization trend is more obvious. Based on this, relevant personnel actively explore the optimization path of high-rise building steel structure construction quality, and further research in the aspects of steel structure reform, manufacturing, design, installation and so on, and urge high-rise steel structure to achieve a new high. At the same time, the construction technology of steel structure with complex structure and wide span is used to support the improvement of the construction quality of the high-rise buildings. As the construction process of CRE International Plaza No. 1 floor tower is taken as the research object, the application of support column base construction technology is discussed, hoping to provide reference for the better development of high-rise buildings [1].
\end{abstract}

\section{Advantages and disadvantages of steel structure in high building}

In recent years, the reason why steel structure has become popular in high building engineering is because of its unparalleled superiority in other structures. The author combines the experience of its own construction, and summarizes the advantages of the steel structure of the high-rise building, which is mainly shown as the following points:

First of all, the steel structure of the high-rise building has some advantages, and it has its own excellent characteristics. Because of its special material, therefore, the construction quality of steel structure is more stable and lower weight, but the material distribution is uniform, and its high strength, high seismic level, its resistance to sudden impact force strong, once the housing construction has such properties, even encountered typhoons, earthquakes and other adverse weather conditions. The building does not collapse, can effectively protect the building.

Secondly, although the strength of steel structure of high-rise building is high, but because of its lighter quality, smaller scale structures, so the convenient transportation and construction, greatly shorten the construction time, the construction time wasting in the uninstall and transport, save the above construction steel structure. For example, the building area of only 1000 square meters of building objects, only 5 workers can be built in just ten days, it can also be combined with concrete construction, and can reduce the construction cycle [2].

Third, because the quality of steel structure of high-rise building is more stable and lower weight, which covers an area of small, compared with the traditional construction materials, steel has 
increased at least 1.5 times the compressive and flexural strength, which can make full use of building space; in addition, steel recycling utilization rate is high, fewer side effects on human health, high safety, construction waste generated less, good effect of energy saving and environmental protection steel, both for environmental protection, human health or security plays an important role.

Although steel has unparalleled advantages, it has to admit that steel structure can not be ignored. It is mainly reflected in the fire resistance of the steel structure of high building, which is compared with the comparison of concrete. When the temperature is higher and higher, the quality of its strength and elasticity of steel will fall greatly image construction effect, which is the steel structure of the high-rise building is currently still can not completely replace one of the causes of concrete and steel material; its corrosion resistance is poor, because the steel material of iron atoms in extremely chemical reaction with the oxygen in the air, in this process, the steel material is extremely prone to rust, which greatly affected the architectural aesthetic effect, reduce the service life of the building [3].

The high-rise building steel structure construction needs to focus on its advantages to be applied, and effective measures to avoid the expansion of its shortcomings, so that steel structure can really promote the construction quality of high-rise buildings, which is also the direction for related personnel in the field of construction.

\section{Combined with the project research of high-rise steel structure supporting frame pedestal base construction technology}

The project site planning object for Cre International Plaza No. four from the ground floor to the ground 30, the total height reached 144 meters. It should be noted that the main structure of the building is a special concrete support, plus a frame scissors wall system, a total of 18 steel pipes, wherein the main steel pipe is branded on the thick raft, and the average section size of the steel pipe is $1600 * 40$. In addition, in each pipe column base is thirty root length is eight hundred mm, weight of 27.76 bolts [4].

During the long construction period, there are some key points in the construction of the project. There are many difficulties encountered in the construction process. The following are the key points and difficulties that the author summed up based on his own construction experience.

First of all, in the installation of steel in the development of construction site, to collect data on the application, in the actual measurement process, some devices can achieve good results, but some equipment control difficulty coefficient is big, like anchor bolt, anchor plate and the supporting frame, the error control in about three mm elevation support face.

Secondly, the main structure of the building is a kind of special concrete pillar and frame shear wall system, a total of 18 steel tubes, each tube column column at thirty root length is eight hundred $\mathrm{mm}$, the quality of bolts $27.76 \mathrm{~kg}$, in the construction, the need to ensure that some are able to anchor pass through the anchor plate is vertical deviation accuracy for each root anchor the part of the construction project are higher, but also must ensure that each anchor does not appear when through the anchor plate tilt, support the accuracy and stability directly affect the construction quality of the anchor bolt can smoothly through the anchor plate.

Third, also need to pay attention to is the need to be buried in the bottom of the concrete column bolt ahead of the material, not only requires each anchor does not appear in this situation through the inclined anchor plate, but also has high stability for anchor bolt and anchor bolt support requirements, to ensure that the thickness of raft anchor support in length three meters, and expand on the concrete casting, also need to pay attention to the position of the anchor bolt and anchor plate center deviation is not more than five mm.

In addition, there are four rows of Steel No. 1 unit building raft bottom, a total of 36 bars, each bar length is nine meters, the total weight of $72 \mathrm{~kg}$, taking into account the weight is heavy, so it needs two people together to complete handling; building 1 , construction period is short so relevant to the needs of the construction personnel reasonable arrange the embedded anchor support frame insertion time, construction time and between raft rebar construction sequence, reasonable 
arrangement of construction schedule, to ensure the construction quality of the completion of a reasonable.

The high-rise building construction process, construction personnel need to firmly grasp the steel structure frame column base construction technology. In full consideration of the traditional steel structure installation and construction method of foundation with the shortcomings of the key process and efficiency of occupation will greatly slow down the construction period on the requirements between the installation and positioning center to steel embedded anchor itself up to a distance of not more than five mm high precision and strong stability, construction personnel to strictly construct and structure of law support and develop the steel plate and welding I-beam composed of base and relying on the new steel structure supporting frame construction technology of column base, greatly enhance the project construction quality and speed, ensure project completion on schedule[5].

(1) Relevant to the needs of the construction personnel production to meet the construction quality of the outside support base, note that in the plate anchor holes are reserved in advance, hire special welding personnel will be on different two layer steel plate welded into a whole with the I-beam, reasonable installation frame base support, after positioning review the supporting frame, positioning without deviation and inclination after the anchor bolt and the supporting frame onto a support base for seamless welding.

(2) When the support frame column base construction technology for construction of steel structures, should pay special attention to the following points: key construction points and do a good job of measuring, which is the key of steel structure supporting frame column base construction. In the whole process of construction, the need for measurement or location for related equipment, measuring the data accuracy and stability will directly affect the construction quality and the completion time of the follow-up project, in order to ensure the measurement data as much as possible to achieve the required accuracy of construction or construction personnel for the measurement result of control requirements the construction unit of each working group together, cooperate together to accomplish the measurement work, which requires personnel to complete the following work:

First, the control points on the property unit provides for review, once found a mistake or error, immediately terminate the follow-up project, to ensure that there are no mistakes again on axis measuring, the measuring of the measuring results immediately even after the review, found the results do not meet building codes or basis, then immediately re measuring or re work links on a step, until the data obtained results meet the specification of construction related construction projects or comply with the position principle.

Second, waterproof construction engineering such as waterproof cushion cushion immediately after the completion of construction project, according to the number of foot support shelf, positioning each support base of the control line, the bottom plate on the projection plate, make measurement of specialized personnel marked meticulous, convenient after consulting or provide experience for other projects. For example, the project site planning object selection in China International Plaza No. four from the ground floor to the ground 30, the total height of 144 meters, after the need for annotation plan making, provide the basis for better construction.

(3) Is to pay special attention to making the supporting frame column base. It should be noted that the main structure of the building is a special concrete support, plus a frame scissors wall system, a total of 18 steel pipes, wherein the main steel pipe is branded on the thick raft, and the average section size of the steel pipe is $1600 * 40$. In addition, in each pipe column base is thirty root length is eight hundred mm, weight of 27.76 bolts, in addition, the foot base here is composed of two pieces of steel material combinations, among them, the lower plate size of $300 \mathrm{~mm}$ multiplied by three mm multiplied by ten mm, while the upper plate it covers an area of not making supporting frame column base.

For the production of support column base, first to $300 \mathrm{~mm}$ multiplied by three mm multiplied by ten mm lower plate draw a cross line in size, $300 \mathrm{~mm} * 300 \mathrm{~mm} * 10 \mathrm{~mm}$ steel plate by welding in lower expansion bolt on the custom, but in the welding process, to set aside anchor bolt hole 4 M12, 
the measurement data in the process will also need to locate the anchor bolt hole. On the other hand, the lower plate material area is $300 \mathrm{~mm} * 300 \mathrm{~mm} * 10 \mathrm{~mm}$, so that the upper plate volume than the lower plate volume to be big, between the upper and lower plate not overhead need two pieces of upper and lower steel I-beam welded together, so that the upper and lower plate is connected into a whole, so all blend into one harmonious whole. The welding method and technology of upper and lower connecting plate can not only affect on the overall stability of steel plate and bridge, will also affect the whole frame and its installation in the whole construction engineering effectiveness and stability.

After the base supporting frame pedestal in measurement data and production, followed by the detailed scientific installation support base. The construction experience tells us that we must install the support base on the bottom of the floor, and wait for the bottom bar to be tied up, then we can say that the construction is coming to an end. It should be noted that the project will support the frame base. According to the axis location as the reference data, the supporting frame base is positioned on the base with a volume of $500 \mathrm{~mm} * 500 \mathrm{~mm} * 90 \mathrm{~mm}$. The base of this $500 \mathrm{~mm}$ $500 \mathrm{~mm} 500 \mathrm{~mm} 90 \mathrm{~mm}$ is made of concrete material. After that, the location of the support frame is checked, and it is found that the positioning is unbiased and no tilt. Then, the anchor bolts and supporting frames are hoisted to the supporting frame base to carry out seamless welding. The complex characters in the nuclear positioning process, needs the help of four expansion bolts on the fixed, while for the second layer above the extremely rebar of reinforced, until all the bottom rebar after re positioning after review before the reinforcement binding, so positioning review, in order to further reduce the error. Until after the confirmation, before the construction can be carried out the next steps. After a series of measurements and a support column base after installation, confirmed that no error, can support the frame for hoisting [6].

\section{Conclusions}

Through the application of high-rise steel structure supporting frame pedestal base construction technology, effectively improve the accuracy of traditional problems of anchor construction technology, construction process, key occupation support poor stability, and has become an important part of improving the quality of high-rise building construction. The relevant personnel also need to support column base construction technology in-depth research and Exploration on the steel structure of the high-rise building, so that in the promotion of high-rise building construction quality improvement plays an important role in the process, let it gradually in the high-rise building in the construction of steel structure to promote, provide a strong impetus for the development of China's construction industry.

\section{References}

[1] Kurita S, Tanizawa H, Morobishi R, et al. Prediction of Maximum Pressures During Uplift Acting On Laminated Rubber Bearings Supporting Base Isolated High-Rise Buildings Subject to Horizontal Seismic Ground Motion[J]. Journal of Structural \& Construction Engineering Transactions of Aij, 2000, 65(529):73-80.

[2] Duan W. Discussion on the installation and demolition of fastener-style steel-pipe supporting frame[J]. Shanxi Architecture, 2017.

[3] Yue-Xiang X U. Discussion on Construction Technology of Longitudinal Structure of Ballastless Track Base Plate[J]. Value Engineering, 2017.

[4] Lin L C. Discussion on the design and Construction Schemes of the Foundation Ditch of the High-rise Buildings[J]. Sci/tech Information Development \& Economy, 2005.

[5] Migra R P. Conceptual definition of a technology development mission for advanced solar dynamic power systems[J]. Final Report Sverdrup Technology Inc Cleveland Oh, 1986.

[6] Constantinescu E, Barman B G. Flexible support structure with composite material spring 
modules mounted directly on frame members and related assembly equipment and methods-microtek III: US, US 6406009 B1[P]. 2002.

A brief introduction to the author:

1. Lei Han, Female, Shandong province, June 14th, 1983. Master degree, Lecturership, Civil Engineering.

2. Heng Zheng, Male, Shandong province, October 2ed, 1981. Master degree, Lecturership, Civil Engineering.

3. Chuanhong Li, Female, Shandong province, December 09th, 1984. Bachelor degree, Lecturership, Civil Engineering. 